Supplementary information:

\title{
Daytime formation of nitrous acid at a coastal remote site in Cyprus indicating a common ground source of atmospheric HONO and NO
}

Hannah Meusel ${ }^{1}$, Uwe Kuhn ${ }^{1}$, Andreas Reiffs ${ }^{2}$, Chinmay Mallik², Hartwig Harder ${ }^{2}$, Monica Martinez ${ }^{2}$, Jan Schuladen ${ }^{2}$, Birger Bohn ${ }^{3}$, Uwe Parchatka ${ }^{2}$, John N. Crowley ${ }^{2}$, Horst Fischer ${ }^{2}$, Thorsten Hoffmann ${ }^{4}$, Ruud Janssen $^{2,5}$, Oscar Hartogensis ${ }^{6}$, Michael Pikridas ${ }^{7}$, Mihalis Vrekoussis ${ }^{7,8,9}$, Efstratios Bourtsoukidis ${ }^{2}$, Bettina Weber $^{1}$, Jos Lelieveld ${ }^{2}$, Jonathan Williams ${ }^{2}$, Ulrich Pöschl ${ }^{1}$, Yafang Cheng ${ }^{1}$, Hang Su ${ }^{1}$

${ }^{1}$ Max Planck institute for Chemistry, Multiphase Chemistry Department, Mainz, Germany

${ }^{2}$ Max Planck Institute for Chemistry, Atmospheric Chemistry Department, Mainz, Germany

${ }^{3}$ Institute for Energy and Climate Research (IEK-8), Research Center Jülich, Jülich, Germany

${ }^{4}$ Johannes Gutenberg University, Inorganic and Analytical Chemistry, Mainz, Germany

${ }^{5}$ MeteoGroup, Wageningen, Netherlands

${ }^{6}$ Wageningen University and Research Center, Meteorology and Air Quality, Wageningen, Netherlands

${ }^{7}$ Cyprus Institute, Energy, Environment and Water Research Center, Nicosia, Cyprus

${ }^{8}$ Institute of Environmental Physics and Remote Sensing - IUP, University of Bremen, Germany

${ }^{9}$ Center of Marine Environmental Sciences - MARUM, University of Bremen, Germany

Correspondence to: Hang Su (h.su@mpic.de)

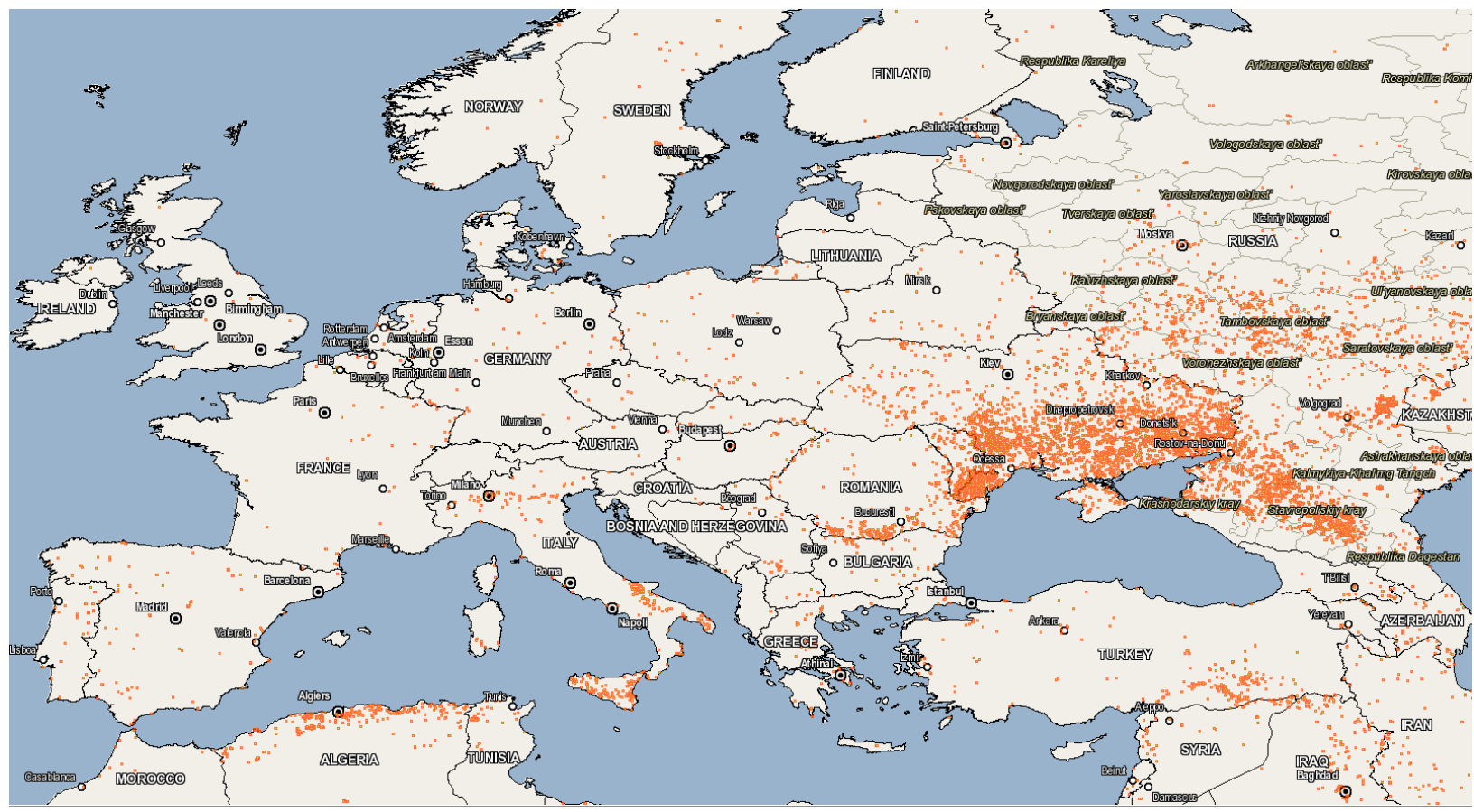

Fig. S1: Fires (red dots) detected during the whole measurement campaign from 7.7.2014 to 3.8.2014 (NASA FIRMS Web fire mapper). 
(a) 0

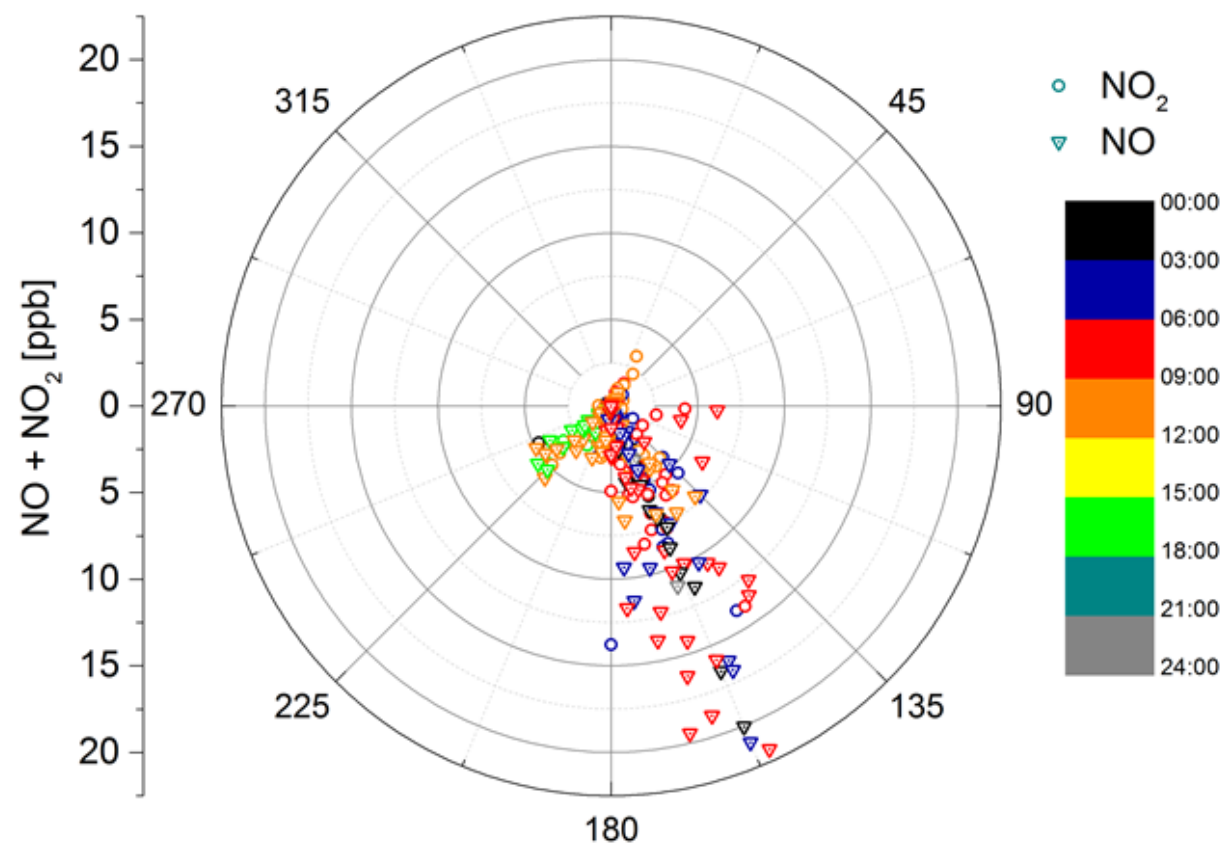

(b)

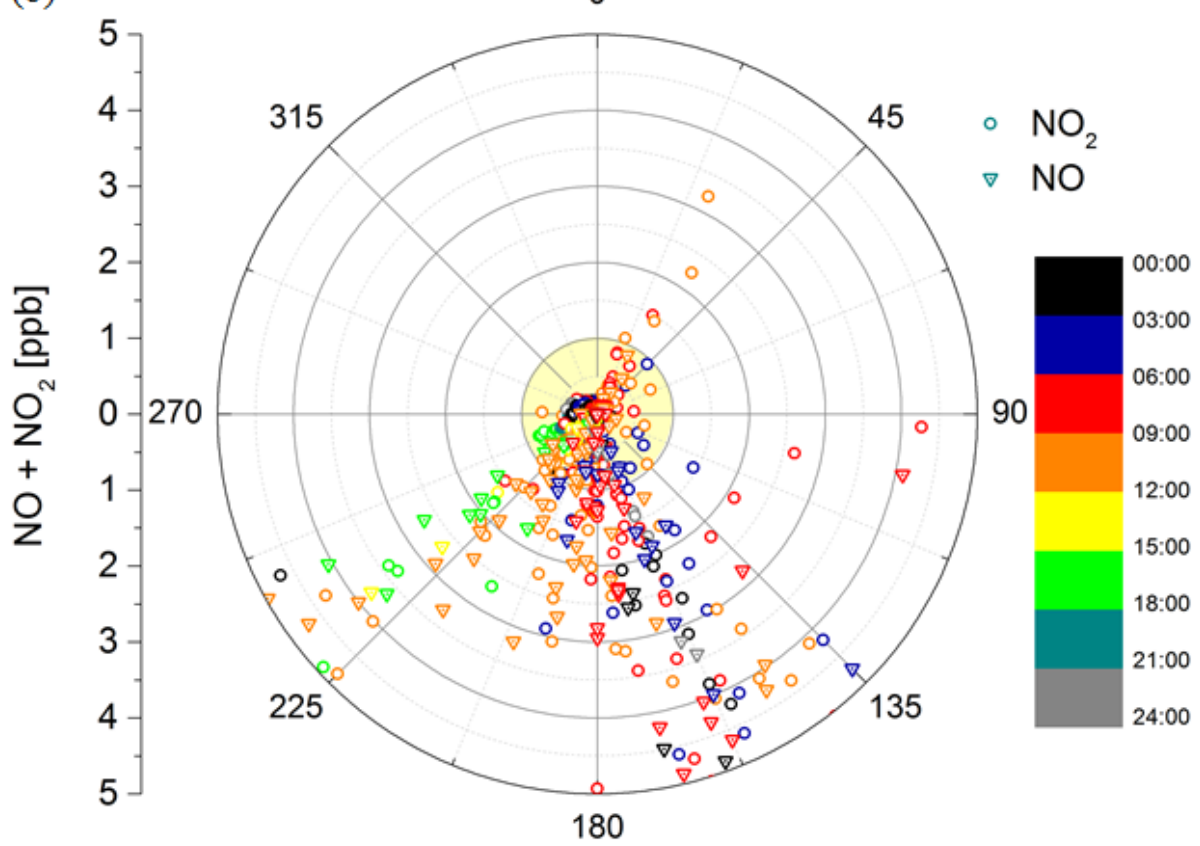

Fig. S2: NOx concentrations in dependence of wind direction and time of day (a) all data, except 5 data points which were between 25 and $50 \mathrm{ppb}$ and b) zoom in to maximum $5 \mathrm{ppb}$ ): Strong morning peaks in $\mathrm{NO}$ and $\mathrm{NO}_{2}$ correlate with wind, coming from SSE (Diesel generator), in the afternoon there were also some higher NOx concentrations which correlate with SW-winds (probably indicating some construction or military cars close to the measurement) or NNE to E (street to the base); these high concentrations were not included in further calculations! Only concentrations up to $1 \mathrm{ppb}$ (for $\mathrm{NO}_{2}$, pale yellow area) and up to $0.5 \mathrm{ppb}$ (for NO) are considered. 

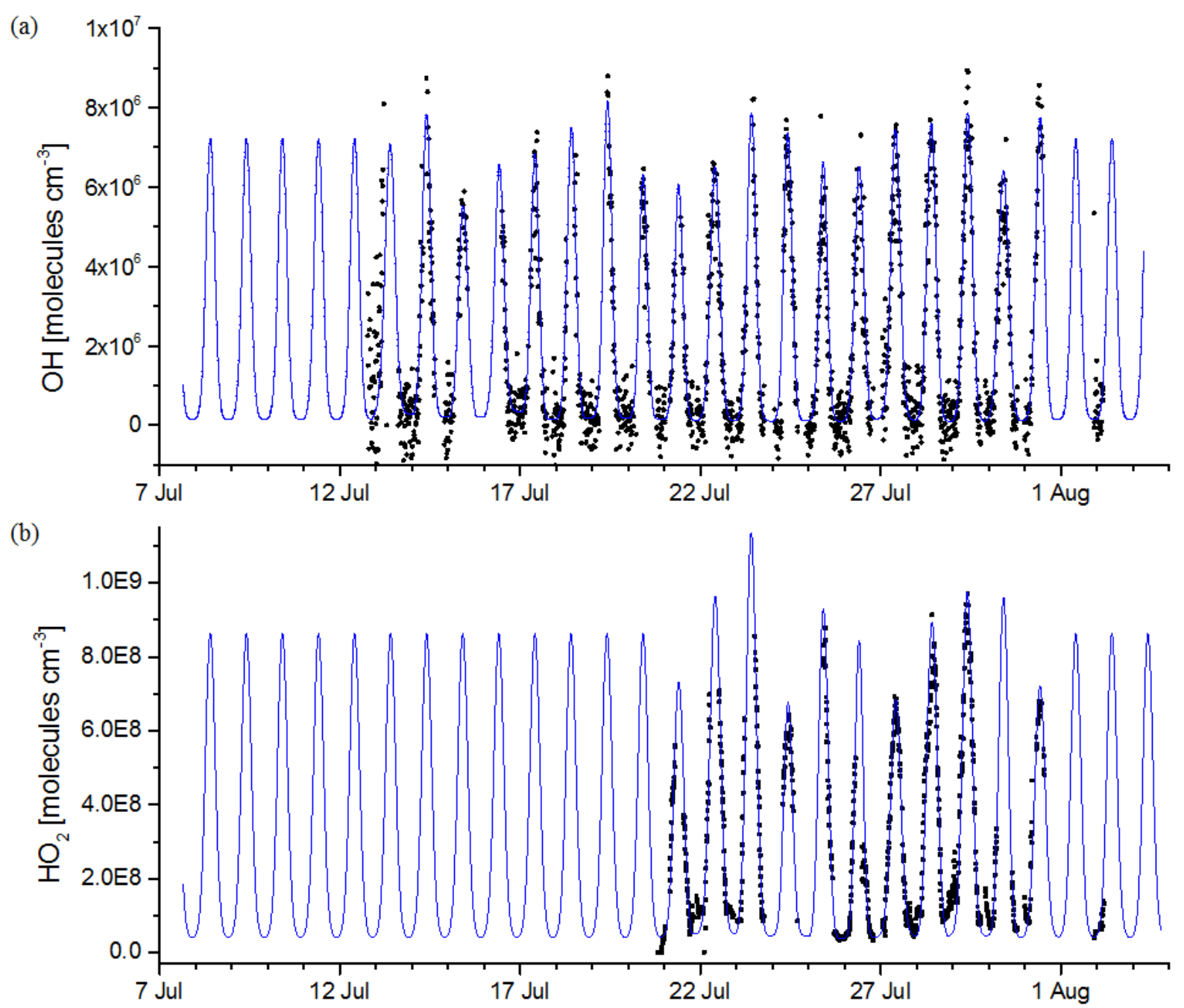

Fig. S3: timeline of $\mathrm{OH}$ and $\mathrm{HO}_{2}$ concentration, black dots indicate real measurement data, blue line is the daily Gauss fit through measurement dots or the average of Gauss fit for those days when no data were available, respectively. 
(a)

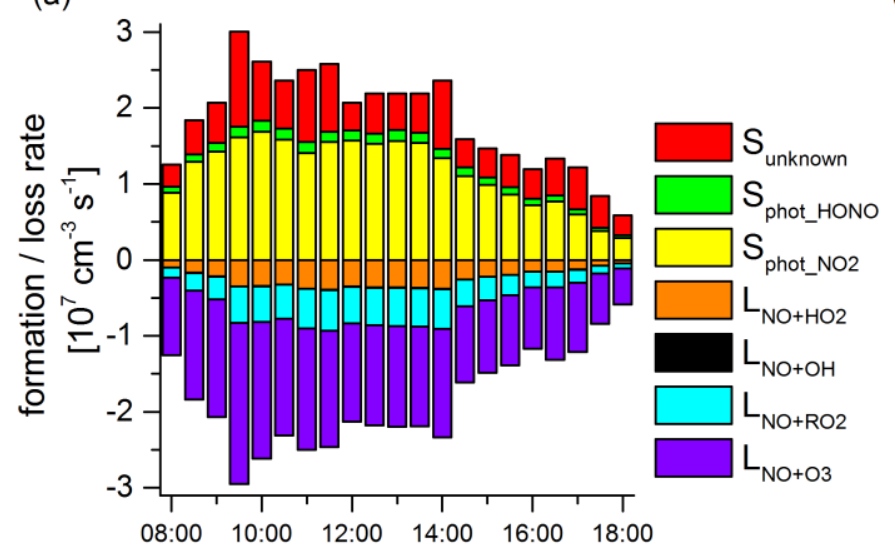

(b)

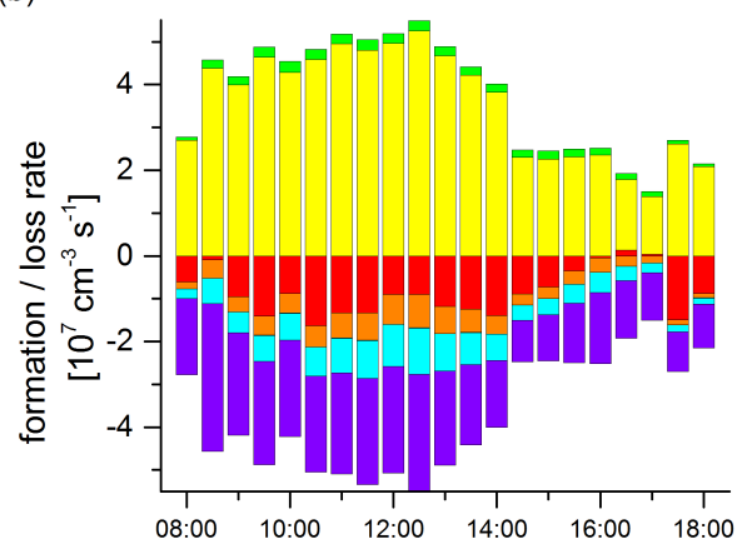

S4: Contributions of production and loss terms as well as the unknown daytime NO source $S_{\text {unknown }}$ for the a) wet and b) dry period. The photolysis of $\mathrm{NO}_{2}$ has the highest contribution to the NO budget. In the wet period the unknown source of $\mathrm{NO}$ is about $40-80 \%$ of the photolysis of $\mathrm{NO}_{2}$. During the dry period there is an unknown sink. The main loss terms are the reaction with $\mathrm{O}_{3}$ followed by the reaction with $\mathrm{RO}_{2}$ and $\mathrm{HO}_{2}$. 